\title{
EXPERIMENTAL ANALYSIS OF MULTINATIONAL GENETIC ALGORITHM AND ITS MODIFICATIONS
}

Gulayeva N. M. -PhD, Associate Professor at the Department of Informatics, National University of "Kyiv-Mohyla Academy", Kyiv, Ukraine.

Yaremko S. A. - Ms. Sc., Assistant Lecturer at the Department of Informatics, National University of "KyivMohyla Academy", Kyiv, Ukraine.

\section{ABSTRACT}

Context. Niching genetic algorithms are one of the most popular approaches to solve multimodal optimization problems. When classifying niching genetic algorithms it is possible to select algorithms explicitly analyzing topography of fitness function landscape; multinational genetic algorithm is one of the earliest examples of these algorithms.

Objective. Development and analysis of the multinational genetic algorithm and its modifications to find all maxima of a multimodal function.

Method. Experimental analysis of algorithms is carried out. Numerous runs of algorithms on well-known test problems are conducted and performance criteria are computed, namely, the percentage of convergence, real (global, local) and fake peak ratios; note that peak rations are computed only in case of algorithm convergence.

Results. Software implementation of a multinational genetic algorithm has been developed and experimental tuning of its parameters has been carried out. Two modifications of hill-valley function used for determining the relative position of individuals have been proposed. Experimental analysis of the multinational genetic algorithm with classic hill-valley function and with its modifications has been carried out.

Conclusions. The scientific novelty of the study is that hill-valley function modifications producing less number of wrong identifications of basins of attraction in comparison with classic hill-valley function are proposed. Using these modifications yields to performance improvements of the multinational genetic algorithm for a number of test functions; for other test functions improvement of the quality criteria is accompanied by the decrease of the convergence percentage. In general, the convergence percentage and the quality criterion values demonstrated by the algorithm studied are insufficient for practical use in comparison with other known algorithms. At the same time using modified hill-valley functions as a post-processing step for other niching algorithms seems to be a promising improvement of performance of these algorithms.

KEYWORDS: multimodal optimization problem, niching genetic algorithms, multinational genetic algorithm, hill-valley function, genetic algorithm convergence, real peak ratio, fake peak ratio.

\section{ABBREVIATIONS}

ASD is an adaptive species discovery;

GA is a genetic algorithm;

HillVallEA is a hill-valley evolutionary algorithm;

HTS is a history-based topological speciation;

$\mathrm{HVcMO}$ is a hill-valley-clustering-based variable mesh optimization;

HVF is a hill-valley function;

MMOP is a multimodal optimization problem;

MNGA is a multinational genetic algorithm;

$\mathrm{MNGA}_{\mathrm{c}_{-} \mathrm{h}_{-} \mathrm{v}}$ is a MNGA with $F_{c_{-} h_{-} v}$;

$\mathrm{MNGA}_{\mathrm{m} \_\mathrm{r}}$ is a MNGA with $F_{m \_} \_v$;

$\mathrm{MNGA}_{\mathrm{m} \mathrm{h}_{\mathrm{v}} \text { rand }}$ is a MNGA with $F_{m_{-} h_{-} v_{-} \text {rand; }}$

$\mathrm{MNGA}^{\mathrm{n}}$ is a MNGA with national selection to the mating pool;

$\mathrm{MNGA}^{\mathrm{w}}$ is a MNGA with weighted selection to the mating pool;

$\mathrm{MNGA}^{\mathrm{m}}$ is a MNGA with mixed selection to the mating pool;

NBC is a nearest-better clustering;

RS-CMSA is a covariance matrix self-adaptation evolution strategy with repelling subpopulations;

SCGA is a species conserving GA;

TCGM_S2 is a GA of tournament crowding based on Gaussian mutation, with S2 parameter set;

TS is a topographical selection;

TSC is a topological species conservation.

\section{NOMENCLATURE} and $y$;

$d(x, y)$ is an Euclidean distance between individuals $x$

$f$ is a fitness function;

$f(s)$ is a fitness value of an individual $s$;

$F_{C \_h \_v}$ is a classic HVF;

$F_{m_{-} h_{-} v}$ is a modified HVF;

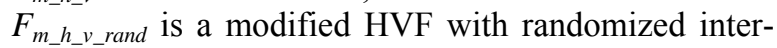
mediate points;

FPR is a ratio of the number of fake peaks found by the algorithm to the total number of species formed by the final population;

$g(k, t)$ is a number of politicians of the $k$-th nation at the $t$-th algorithm step;

$G P$ is a number of real global peaks found in one run of the algorithm;

$G P R$ is a ratio of the number of real global peaks found by the algorithm to the total number of global peaks to be localized;

$g r=\left[g r_{1}, \quad g r_{2}, \ldots, g r_{K}\right]$ is a sample array, $0<g r_{1}<g r_{2}<\ldots<g r_{K}<1$;

$i_{j}$ is a $j$-th politician;

$K$ is a size of $g r$ and a number of intermediate points used by HVF;

$L P$ is a number of real local peaks found in one run of the algorithm; 
$L P R$ is a ratio of the number of real local peaks found by the algorithm to the total number of local peaks to be localized;

$n$ is a search space dimension;

$N P$ is a number of real peaks found in one run of the algorithm;

NSeeds is a power of Seeds, i.e. a number of species or, equivalently, a number of peaks (real and fake) found in one run of the algorithm;

$O_{\varepsilon}\left(x^{*}\right)$ is an $\varepsilon$-neighborhood of the point $x^{*}$;

$<p_{0}, p_{1}, p_{2}, \ldots, p_{K}, p_{K+1}>$ is an ordered list of points used by $\mathrm{HVF}, p_{i} \in X \subseteq R^{n}$;

$p_{0}$ is a first test point;

$P_{c}$ is a probability of crossover;

$p_{i}$ is an $i$-th intermediate point, $0<i<K+1$;

$p_{i}^{j}$ is a $j$-th coordinate of the $i$-th point;

$p_{K+1}$ is a second test point;

$p l_{k}(t)$ is a policy of the $k$-th nation at the $t$-th algorithm step;

$P_{m}$ is a probability of mutation;

$P R$ is a ratio of the number of real peaks found by the algorithm to the total number of peaks to be localized;

$S$ is a set of individuals encoding $X \subseteq R^{n}$;

$s_{i}$ is an individual encoding point $p_{i}, 0 \leq i \leq K+1$;

Seeds is a set of the best individuals of each species;

SucRuns is a percentage of successful runs of the algorithm;

$\delta$ is a function accuracy parameter;

$\xi$ is a random value from $(0,1)$;

$\sigma$ is an argument accuracy parameter.

\section{INTRODUCTION}

Niching GAs, based on the phenomenon of speciation and specialization in natural ecosystems, are one of the most popular approaches to solve MMOPs. These problems aim to find multiple extremums (global, local) of a given function and arise in many areas of science and technology, see [1-5] for examples.

It can be shown that solving an arbitrary, including multimodal, optimization problem in the form

$$
F(x) \rightarrow \max , x \in X \subseteq R^{n}
$$

reduces to solving by a GA an optimization problem in the form

$$
f(s) \rightarrow \max , s \in S \text {. }
$$

Here with, an arbitrary feasible solution of problem (2) is called an individual of the population, and it is said about genotype and phenotype of the individual. The objective function of (2) is used to estimate the quality of solution of (1); crossover (the exchange of segments between different solutions) and mutation (disturbance) operators ensure transition from one solution to another.
A niche in GA is a subdomain of the search space (a region around a certain optimum of the fitness function), and species is a subpopulation of individuals located in a given niche. Niching GAs tend to structure population into stable subpopulations (species) in the search space in a way that each subpopulation is formed around one of the sought optimums. To date, several dozen niching GAs of different performance reflecting various approaches to solve MMOPs have been developed. Surveys of niching GAs and their classifications are available at $[1,6,7]$.

In recent years topological niching GAs are of growing interest. To capture the landscape topography and identify basins of attraction for given individuals the topological niching GAs analyze relationships between locations and fitness values of individuals. Based on the basin identification method these algorithms can be roughly classified at the algorithms based on TS [8, 9], algorithms based on NBC [10-13], and algorithms using HVF. Last class includes but not limited to MNGA [14, 15], TSC and TSC2 [16, 17], ASD [18], HTS [19], HillVallEA [20, 21], HVcMO [22, 23], RS-CMSA [24, 25].

The object of study is a niching GA as a method to solve MMOPs.

The subjects of study are the HVF, MNGA and how MNGA parameters affect algorithm performance.

The purpose of the work is the development and performance analysis of MNGA and its modifications. Recall that the experimental analysis of heuristic algorithm performance is to evaluate statistical data collected as a result of conducting a series of independent runs of the algorithm for each problem from the benchmark suite.

\section{PROBLEM STATEMENT}

In this paper the MMOP (1) is considered in the following formulation. Let $F: X \rightarrow R$ be a function defined on some set $X \subseteq R^{n}$. A point $x^{*} \in X$ is called a point of local maximum of $F$ over $X$ if there exists a number $\varepsilon>0$ such that $\forall x \in X \cap O_{\varepsilon}\left(x^{*}\right): F\left(x^{*}\right) \geq F(x)$. A point $x^{*} \in X$ is called a point of global maximum of $F$ over $X$ if $\forall x \in X$ : $F\left(x^{*}\right) \geq F(x)$. The problem is to find all points of local and global maxima and the values of function $F$ at these points.

The MNGA analysis is to compute well-known criteria characterizing the number and accuracy of problem solutions found by the MNGA and to compare the criterion values obtained for various values of the MNGA parameters.

\section{REVIEW OF THE LITERATURE}

A significant drawback of many niching algorithms is so-called niche radius problem. The performance of radiibased niching algorithms heavily depends on the niche radius value while estimation of this value is a complex task requiring prior knowledge of the search space landscape $[1,6]$. As opposed to radii-based niching algorithms, the MNGA presented in [14, 15] divides popula- 
tion into subpopulations without using the niche radius concept. To determine whether two individuals occupy the same niche (whether the points encoded by these individuals are in the neighborhood of the same extremum) the fitness-topology function HVF is used. This function analyzes the search space landscape between two points based on the fitness values of individuals encoding points located on the straight line that connects two test points.

In MNGA the following metaphor is used. The population of individuals represents the world (the entire population of the planet), each subpopulation represents the nation, and the fittest individuals in the subpopulation represent the government of the nation; these individuals are referred to as the politicians. The government determines the policy of the nation, which is a single point representing the peak the nation is formed around; this point is the centroid of the subpopulation fittest individuals. Policy calculation is needed to determine possible migrations of individuals between nations as well as to distinguish nations from each other. The evolution of the world obeys the following rules.

1. Migration. This rule regulates movement of individuals between nations and creation of new nations in "uninhibited" areas of the search space.

2. Merge. Nations are merged when they are formed around the same extremum.

3 . Selection to the mating pool. The following modifications of binary tournament selection are considered.

1) Weighted selection. In this case fitness value of an individual is divided by the total number of individuals in its nation. This approach reduces the probability for a nation to die out because of small subpopulation size.

2) National selection is conducted within each nation, therefore, the number of individuals in a nation after selection remains unchanged. This implies that migration is the only way to change the nation size.

3) Mixed selection is a combination of weighted and national selections.

4. Election. This rule describes how the government of a nation is elected and how its policy is calculated. Note that formula $p l_{k}(t)=\frac{1}{g(k, t)} \sum_{j=1}^{g(k, t)} i_{j}$ is computed coordinatewise. If the number of individuals in a nation is less than predefined value $g$, then the number of politicians is equal to the number of individuals in the subpopulation.

5. Mating. Only individuals belonging to the same nation may produce offspring. This limitation is because the crossover of two individuals located in the neighborhoods of two different optima may produce an offspring much worse than each of the parents. The mutation operator that adds noise generated by normal distribution to an individual is called in [15] the mutation based on the distance policy; this name looks reasonable as the operator provides minor changes to individuals that are close to the nation policy and significant changes to individuals located far from it. In literature, this operator is also known as Gaussian mutation. In [14] it is proposed to perform mutations within nations, i.e. an offspring is accepted (C) Gulayeva N. M., Yaremko S. A., 2021 DOI 10.15588/1607-3274-2021-2-8 only if it occupies the same niche as its parent. To reduce the algorithm execution time, this restriction was not applied in our research.

6. Initialization of the start nation. At the start of the algorithm, all individuals belong to the same initial nation.

MNGA works as follows. In every generation, each individual is compared to the policy of its nation. If the individual and the policy are located around different optima, the individual migrates to the nation with policy in the individual's peak neighborhood. If such a nation does not exist, the individual founds a new one; this nation corresponds to a potentially new peak the individual is approaching. If a nation with a very small number of individuals is formed at the end of the migration process, this nation is strengthened by new individuals generated from the nation policy with the use of Gaussian mutation. Instead, the worst fitness individuals of other nations are removed from the population. After completion of all necessary migrations, the pairwise comparisons of policies of all nations are carried out to ensure there are no nations following the same peak; if two nations around the same peak are found, the corresponding subpopulations are merged. Thereafter, standard actions are performed to move to the next generation, i.e. selection to the mating pool and applying genetic operators. The MNGA scheme is provided below.

0 . Encoding of solutions.

1. Initialization. The initial population is generated randomly.

2. Fitness calculation for all individuals in the population.

3. Initialization of the start nation. Determining politicians and calculation of the policy.

4. Migrations of individuals.

5. Recalculation of all nation policies.

6. Strengthening small nations.

7. Merging nations.

8. Selection to the mating pool.

9. Applying genetic operators (crossover, mutation).

10. Fitness calculation for all obtained offspring.

11. If the stop condition is fulfilled, then goto step 12 , otherwise goto step 4.

12. Stop the algorithm.

To implement processes of migration of individuals and merging of nations the HVF is used. This function determines the positional relationship of two selected individuals, in fact of points encoded by these individuals. HVF returns TRUE if these points are located in the neighborhoods of different maxima (there is a "valley" in the fitness function landscape between the points). HVF returns FALSE if these points are located in the neighborhood of the same maximum (there is a "hill" in the fitness function landscape between the points).

The idea of the HVF is as follows. A set of points disposed on the line connecting two test points is generated; to calculate these intermediate points a predefined array $g r$ is used. If fitness of all intermediate individuals is not less than fitness of the worst of the test individuals, these 
test individuals are considered to be located around the same maximum (the HVF returns FALSE); otherwise they are considered to be located around different maxima (the HVF returns TRUE).

The $F_{c_{-} h_{-} v}$ computation scheme proposed in $[14,15]$ is given below.

1. Put $i=1$; found $=$ FALSE.

2. If $i \leq K$ and found $==$ FALSE, then goto step 3 (intermediate point calculation); otherwise goto step 6 .

3. For each $j$ from 1 to $n$ do: $p_{i}^{j}=p_{0}^{j}+\left(p_{K+1}{ }^{j}-p_{0}{ }^{j}\right)^{*} g r_{i}$.

4. If $f\left(s_{i}\right)<\min \left(f\left(s_{0}\right), f\left(s_{K+1}\right)\right)$, then put found = TRUE.

5. Put $i=i+1$.

6. Return found.

For example, let $n=2$ and $g r=[0.25,0.5,0.75]$. Then, to determine the relative position of points $(0,1)$ and $(1$, $2)$, the intermediate points $(0.25,1.25),(0.5,1.5)$ and $(0.75,1.75)$ will be analyzed by the algorithm above.

In [15] the array $[0.25,0.5,0.75]$ is used to ensure the migration process, and the array $[0.02,0.25,0.5,0.75$, $0.98]$ is used to ensure the merging process. The extension of the sample array by two extra points is explained by the fact that merging subpopulations is more drastic operation than migration of an individual from one nation to another.

\section{MATERIALS AND METHODS}

In some cases the $F_{c h}$ v return values are wrong. Let us consider functions $F_{1}$ and $F_{2}$ of dimension 1 , see Section 4, and determine the positional relationship of the points 0.13 and 0.97 by the $F_{c_{-} h_{-} v}, g r=[0.02,0.25,0.5$, $0.75,0.98]$. Notice that each of the functions has five peaks and test points are located on the first and the fifth peaks with respect to the left-to-right peak numeration alongside the $X$-axis. But $F_{c h_{-} v}(0.13,0.97)=$ FALSE. This means that points 0.13 and 0.97 are in the neighborhood of the same peak according to $F_{c h v}$. Table 1 provides $F_{1}$ and $F_{2}$ values at the test and intermediate points.

Table $1-$ Values of $F_{1}$ and $F_{2}$ at the points analyzed by HVF

\begin{tabular}{|l|l|l|l|}
\hline \multicolumn{1}{|c|}{$i$} & \multicolumn{1}{c|}{$p_{i}$} & \multicolumn{1}{c|}{$F_{1}$} & \multicolumn{1}{c|}{$F_{2}$} \\
\hline 0 & 0.13 & 0.50036 & 0.49939 \\
\hline 1 & 0.1468 & 0.16654 & 0.16575 \\
\hline 2 & 0.34 & 0.28038 & 0.24749 \\
\hline 3 & 0.55 & 0.125 & 0.08061 \\
\hline 4 & 0.76 & 0.04124 & 0.01605 \\
\hline 5 & 0.9532 & 0.09102 & 0.01881 \\
\hline 6 & 0.97 & 0.00876 & 0.00170 \\
\hline
\end{tabular}

The first proposed HVF modification $F_{m_{-} h_{-} v}$ is the following. Test points are considered to be located in the neighborhood of the same maximum if, moving along the list $<p_{0}, p_{1}, p_{2}, \ldots, p_{K}, p_{K+1}>$ from $p_{i}$ to $p_{i+1}, 0 \leq i \leq K+1$, fitness changes of individuals encoding these points conform to one of the rules below:

- from a smaller value to a bigger one;

- from a bigger value to a smaller one;

- from a smaller value to a bigger one and again to a smaller value.
Test points are considered to be located in the neighborhoods of different maxima in all other cases.

As an example, let test points $p_{0}, p_{K+1}$ such that $f\left(s_{0}\right)=2$ and $f\left(s_{K+1}\right)=1$ be given. The above modification considers these points as points located around the same maximum if the list of fitness values $<2,3,4,5,7,3,1>$ is analyzed, and as points located around different maxima if the list of fitness values $<2,3,5,3,7,4,1>$ is analyzed.

It is readily seen that $F_{m_{-} h_{-} v}$ returns correct value for the above example defined for $F_{1}$ and $F_{2}$ test functions: $F_{m \_ \text {_ } v}(0.13,0.97)=$ TRUE.

Assume that all the points (test as well as intermediate) are related to individuals of equal fitness. Notice that in this case the $F_{c_{-} h_{-} v}$ treats test points as being located around the same maximum (assuming a plateau), and the $F_{m_{-} h_{-} v}$ treats them as being located around different maxima (assuming existence of neighbor peaks). In general, the presence of plateaus in the fitness function landscape should be avoided since in this case GA can not compare individuals properly.

There exist cases when both $F_{c_{-} h_{-} v}$ and $F_{m_{-} h_{-} v}$ return wrong values. For instance, points 0.09 and 0.91 lie on different peaks of functions $F_{1}$ and $F_{2}$ of dimension 1 , but they are in the neighborhood of the same peak according to both $F_{c_{-} h_{-} v}$ and $F_{m_{-} h_{-} v}$ when $g r=[0.02,0.25,0.5,0.75$, 0.98 ] is used: $F_{c_{-} h_{-} v}(0.09,0.91)=$ FALSE and $F_{m_{-} h_{-} v}(0.09$, $0.91)=$ FALSE. Table 2 provides $F_{1}$ and $F_{2}$ values at the test and intermediate points. The $F_{1}$ graph with circles designating all target points is given in Fig. 1.

Table 2 - Values of $F_{1}$ and $F_{2}$ at the points analyzed by HVF

\begin{tabular}{|l|l|l|l|}
\hline \multicolumn{1}{|c|}{$i$} & \multicolumn{1}{|c|}{$p_{i}$} & \multicolumn{1}{|c|}{$F_{1}$} & \multicolumn{1}{c|}{$F_{2}$} \\
\hline 0 & 0.09 & 0.92837 & 0.92817 \\
\hline 1 & 0.1064 & 0.97009 & 0.97000 \\
\hline 2 & 0.2950 & 0.98165 & 0.90403 \\
\hline 3 & 0.5 & 1.0 & 0.70711 \\
\hline 4 & 0.705 & 0.98165 & 0.44425 \\
\hline 5 & 0.8936 & 0.97009 & 0.24794 \\
\hline 6 & 0.91 & 0.92837 & 0.22414 \\
\hline
\end{tabular}

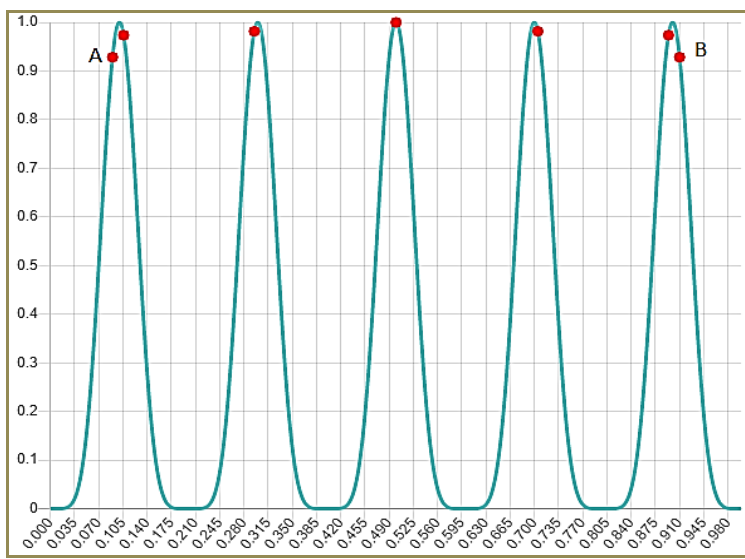

Figure 1 - Graph of $F_{1}$ with points from Table 2

The second proposed HVF modification $F_{m_{-} h_{-} v_{-} \text {rand }}$ is to add random values $\xi_{1}, \xi_{2}$ to the sample array $g r=[0.25$, $0.5,0.75]$; these random values should be generated at each iteration of the algorithm. Such a dynamic array re- 
duces the probability of wrong values returned by the $F_{m \_h \_}$as far as different sets of intermediate points may be used for two test points. In particular, in the example above there could be generated the sample array $g r=[0.25$, $0.35,0.5,0.6,0.75]$ ensuring the $F_{m_{-} h_{-} v}$ correct return value. Table 3 provides $F_{1}$ and $F_{2}$ values at the test and intermediate points. The $F_{1}$ graph with circles designating all target points is given in Fig. 2 .

Table 3 - Values of $F_{1}$ and $F_{2}$ at the points analyzed by HVF

\begin{tabular}{|l|l|l|l|}
\hline \multicolumn{1}{|c|}{$i$} & \multicolumn{1}{|c|}{$p_{i}$} & \multicolumn{1}{|c|}{$F_{1}$} & $F_{2}$ \\
\hline 0 & 0.09 & 0.92837 & 0.92817 \\
\hline 1 & 0.295 & 0.98165 & 0.90403 \\
\hline 2 & 0.377 & 0.00195 & 0.00165 \\
\hline 3 & 0.5 & 1 & 0.70711 \\
\hline 4 & 0.582 & 0.00047 & 0.00029 \\
\hline 5 & 0.705 & 0.98165 & 0.44425 \\
\hline 6 & 0.91 & 0.92837 & 0.22414 \\
\hline
\end{tabular}

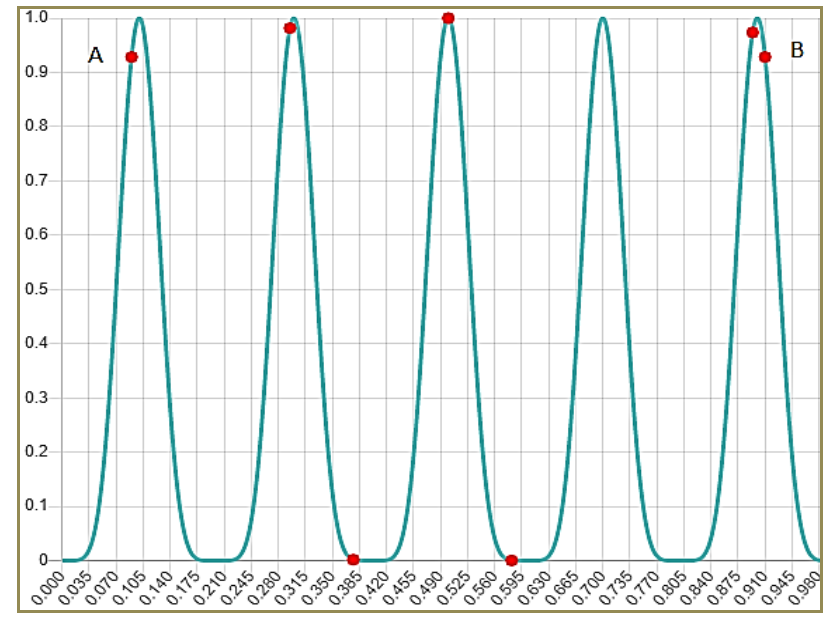

Figure 2 - Graph of $F_{1}$ with points from Table 3

Preliminary tests revealed significant differences in the $F_{c_{-}{ }_{-} v}, F_{m_{-} h_{-} v}$ and $F_{m_{-} h_{-}{ }_{-} \text {rand }}$ responses. The statistics of these function calls for one MNGA run on the $F_{1}$ test function is shown in Table 4. Following sections provide the benchmarking of the MNGA with $F_{c h v}, F_{m h_{v} v}$ and $F_{m \_}{ }_{-}{ }_{-}$rand .

Table 4 - Differences in responses of $F_{c_{-} h_{-} v}, F_{m_{-} h_{-} v}, F_{m_{-} h_{-} v_{-} \text {rand }}$ for one MNGA run on $F_{1}$

\begin{tabular}{|l|l|l|}
\hline Number of different responses for: & \multicolumn{1}{|c|}{$n=1$} & \multicolumn{1}{|c|}{$n=3$} \\
\hline$F_{c h v}$ and $F_{m h v}$ & 2616 & 1020942 \\
\hline$F_{c h v}$ and $F_{m h v \text { rand }}$ & 1900 & 1114164 \\
\hline$F_{m h v}$ and $F_{m h v \text { rand }}$ & 872 & 253978 \\
\hline Total number of HVF calls: & 23265 & 5209793 \\
\hline
\end{tabular}

\section{EXPERIMENTS}

Recall that in this paper the experimental analysis of performance of the MNGA and its modifications is used. Thus, test problems and performance criteria should be defined.

Test suite of benchmark functions used in this research is given below.

1) Equal Maxima function (Deb’s 1):

$$
\begin{gathered}
y=F_{1}\left(x_{1}, x_{2}, \ldots, x_{n}\right)=\frac{1}{n} \sum_{i=1}^{n} \sin ^{6}\left(5 \pi x_{i}\right), \\
0 \leq x_{i} \leq 1, i=\overline{1, n} .
\end{gathered}
$$

The function has $5^{n}$ equally spaced global maxima.

2) Decreasing Maxima function (Deb’s 2):

$$
\begin{gathered}
y=F_{2}\left(x_{1}, x_{2}, \ldots, x_{n}\right)=\sum_{i=1}^{n} e^{-2(\ln 2)\left(\frac{x_{i}-0.1}{0.8}\right)^{2}} \sin ^{6}\left(5 \pi x_{i}\right), \\
0 \leq x_{i} \leq 1, i=\overline{1, n} .
\end{gathered}
$$

The function has $5^{n}$ equally spaced maxima of different heights.

3) Uneven Maxima Function (Deb's 3):

$$
\begin{gathered}
y=F_{3}\left(x_{1}, x_{2}, \ldots, x_{n}\right)=\frac{1}{n} \sum_{i=1}^{n} \sin ^{6}\left(5 \pi\left(x_{i}^{0.75}-0.05\right)\right), \\
0 \leq x_{i} \leq 1, i=\overline{1, n} .
\end{gathered}
$$

The function has $5^{n}$ global maxima that are at different distances from each other, and the distance between the points of maximum increases with increasing value of the argument.

4) Uneven Decreasing Maxima function (Deb’s 4):

$$
\begin{gathered}
y=F_{4}\left(x_{1}, x_{2}, \ldots, x_{n}\right)= \\
=\sum_{i=1}^{n} e^{-2(\ln 2)\left(\frac{x_{i}-0.08}{0.854}\right)^{2}} \sin ^{6}\left(5 \pi\left(x_{i}^{0.75}-0.05\right)\right) \\
0 \leq x_{i} \leq 1, i=\overline{1, n} .
\end{gathered}
$$

The function has $5^{n}$ maxima of different heights that are at different distances from each other, and the distance between the points of maximum increases with increasing value of the argument.

5) Six-Hump Camel Back function:

$$
\begin{gathered}
y=F_{5}\left(x_{1}, x_{2}\right)= \\
=-\left(\left(4-2.1 x_{1}^{2}+\frac{x_{1}^{4}}{3}\right) x_{1}^{2}+x_{1} x_{2}+4\left(x_{2}^{2}-1\right) x_{2}^{2}\right), \\
-3 \leq x_{1} \leq 3,-2 \leq x_{2} \leq 2 .
\end{gathered}
$$

The function has 2 global and 4 local maxima.

6) Griewangk's function is considered in the following form:

$$
\begin{gathered}
y=F_{6}\left(x_{1}, x_{2}, \ldots, x_{n}\right)=n-\left(\sum_{i=1}^{n} \frac{x_{i}^{2}}{4000}-\prod_{i=1}^{n} \cos \left(\frac{x_{i}}{\sqrt{i}}\right)+1\right), \\
-600 \leq x_{i} \leq 600, i=\overline{1, n} .
\end{gathered}
$$

The function has 1 global and many local maxima, and the height of the local maxima decreases with increasing distance from the global maximum. 
7) Rastrigin's function is considered in the following form:

$$
\begin{gathered}
y=F_{7}\left(x_{1}, x_{2}, \ldots, x_{n}\right)=\sum_{i=1}^{n}\left(10 \cos \left(2 \pi x_{i}\right)-x_{i}^{2}\right)-10 n, \\
-5.12 \leq x_{i} \leq 5.12, i=\overline{1, n} .
\end{gathered}
$$

The function has 1 global and $10^{n}$ local maxima, and the height of the local maxima decreases with increasing distance from the global maximum.

8) Modified Rastrigin's function:

$$
\begin{gathered}
y=F_{8}\left(x_{1}, x_{2}\right)=-10-9 \cos \left(6 \pi x_{1}\right)-10-9 \cos \left(8 \pi x_{2}\right), \\
0 \leq x_{1}, x_{2} \leq 1 .
\end{gathered}
$$

The function has 12 global maxima.

9) Xin-She Yang's function:

$$
\begin{gathered}
y=F_{9}\left(x_{1}, x_{2}, \ldots, x_{n}\right)=\left(\sum_{i=1}^{n}\left|x_{i}\right|\right) \exp \left(-\sum_{i=1}^{n} x_{i}^{2}\right), \\
-10 \leq x_{i} \leq 10, i=\overline{1, n} .
\end{gathered}
$$

The function has several global maxima located at a small distance from each other. In particular, for $n=1$ the function has 2 global maxima, and for $n=2$ the function has 4 global maxima.

Detailed description and plots of the functions above can be found in $[26,27]$.

To specify the performance criteria we begin with two definitions: the algorithm stop conditions and whether the extremum is found when the algorithm stops.

GA stops if either population convergence is detected, i.e. the changes in the average population fitness value do not exceed 0.0001 over the last 10 generations, or 40000 algorithm iterations are carried out. This means that if convergence was not detected the algorithm has been terminated after the specified number of iterations. The algorithm run stopped under the convergence condition is called successful.

The maximum is found if the algorithm convergence is detected and there is at least one individual of the final population such that the individual fitness value differs from the sought maximum value at most $\delta$ and the point encoded by this individual is located within the maximum's neighborhood of radius $\sigma$. Let us set $\delta=0.01$ and $\sigma=0.01$ for all test functions.

As stated in [28], when algorithm stops under any condition including convergence, individuals of the final population may be located not only in the small radius neighborhoods of function peaks but individuals may also form clusters on the peak slopes and even in the valleys. Thus, to analyze the algorithms, standard performance criteria are used as well as proposed in [28] FPR criterion that in fact estimates number of clusters formed by individuals located far from the sought maxima. Note that big value of FPR criterion is a significant drawback of a niching algorithm as far as it makes use of such algorithms impractical for problems of finding all (local, global) maxima.
To determine species (and, consequently, niches) formed by the final population the algorithm of [28] presented below is used; $\varepsilon=0.03$.

1. Put Seeds $=\varnothing$.

2. Choose the best unprocessed individual $s$ from the population; mark it as the processed one: $s^{*}$.

3. Put found $=$ FALSE.

4. If there exists an individual $s \in$ Seeds such that $d\left(s^{*}, s\right) \leq \varepsilon$, then put found $=$ TRUE; otherwise, create a new species with the best individual $s^{*}$ : put Seeds= SeedsU $\left\{s^{*}\right\}$.

5. If unprocessed individuals are remained in the population, then goto step 2 .

To separate real species from the fake ones the elements from Seeds should be compared with real peaks of the fitness function using parameters $\delta$ and $\sigma$.

The criteria calculated for each run of the algorithm are the following ones: NSeeds, NP, GP, LP, PR, GPR, $L P R, F P R$. Note that $N P=G P+L P, 0 \leq P R \leq 1,0 \leq G P R \leq 1$, $0 \leq L P R \leq 1,0 \leq F P R \leq 1$. The $F P R$ criterion is calculated as $F P R=\frac{N S e e d s-N P}{N \text { Seed }}$.

For algorithm analysis average values of the $P R, G P R$, $L P R, F P R$ criteria are computed over all runs as well as the SucRuns criterion; the SucRuns is computed as the ratio of the number of successful runs to the total number of runs, in percent. Criterion values of unsuccessful runs are not used to calculate averages; recall that the unsuccessful runs are the runs stopped under the condition of reaching maximum iteration number.

The software implementation of the MNGA with the classic HVF and its both modifications was developed. The criteria above were computed with the following purposes. First, to tune the parameters of the MNGA with $F_{c \_}{ }_{-} v$. Secondly, to conduct comparative analysis of the MNGA with $F_{c_{-} h_{-} v}, F_{m_{-} h_{-} v}$ and $F_{m_{-} h_{-}{ }_{-} \text {rand }}$.

To calculate averages of the criteria above there were conducted 10 runs of the algorithm for each set of parameter values and for each benchmark problem. Note that the initial population is the same for all sets of parameter values at the $i$-th run; this guarantees the same start point for corresponding runs of the algorithms using different sets of parameter values.

The authors of this research tried to follow the [14, 15] recommendations on setting the algorithm parameter values. If such recommendations were not provided in $[14,15]$, the algorithm parameter values have been set based on the authors' experience or by conducting experiments. The predefined MNGA parameter values used in this research are listed below.

- Number of individuals in the population: 500 .

- Number of individuals in the government: 8 .

- Array to implement migration of individuals and merging of nations: $-[0.02,0.25,0.5,0.75,0.98]$ for functions $F_{c_{-} h_{-} v}$ and $F_{m_{-} h_{-}} v$ 


$$
\text { - }[0.25, \quad 0.5,0.75] \cup\left\{\begin{array}{lll}
\xi_{1}, & \left.\xi_{2}\right\} & \text { for function }
\end{array}\right.
$$

$F_{m \_-v_{-} \text {rand }}$.

In [15], small nations are strengthened by the nation policy mutants, i.e. by addition of a small noise to the policy of the nation. To reduce the algorithm computation complexity the zero noise is used in our research, i.e. small nations are supported by copies of their policies. Since there is no information in $[14,15]$ about nations to be small or large, we define the small nation as a nation with population size less than $30 \%$ of the average number of individuals per nation at the current algorithm iteration, and the large nation as a nation with population size exceeding $50 \%$ of the average number of individuals per nation at the current algorithm iteration. This implies that the number of policy copies strengthening a small nation ensures population size of this nation to be not less than $30 \%$ of the average number of individuals per nation at the current algorithm iteration.

Let us remark that step 5 of the MNGA (the recalculation of all nation policies) is not specified in $[14,15]$. We have added this step to ensure the use of actual nation policies while strengthening small nations and merging nations.

Further on, the following MNGA parameter values are analyzed experimentally.

- Encoding methods: real numbers and Gray codes encoding sample points to three decimal places. Notice that binary codes are used in [14] and real numbers are used in [15].

- Selection to the mating pool: the weighted selection, the national selection and the mixed selection. For mixed selection $50 \%$ of individuals are selected using weighted selection and $50 \%$ of individuals are selected using national selection [15].

- Genetic operators used for binary encoding are onepoint crossover and density mutation. The analyzed values of $P_{c}$ are $0.6,0.8,0.9$ and 1 . The analyzed values of $P_{m}$ are $0.001,0.01$ and 0.025 . In [14] values $P_{c}=0.9$ and $P_{m}=0.025$ are recommended. Gaussian density mutation is the only genetic operator used for encoding in real numbers, $P_{m}=1$ [15]. In this case noise determined by standard normal distribution is added to each gene encoded variable.

Generally, 39 parameter sets are analyzed in this research.

For MNGA parameter tuning the $F_{1}-F_{4}$ functions are used. These functions have different properties, e.g. existence of only global maxima $\left(F_{1}, F_{3}\right)$ or global and local maxima $\left(F_{2}, F_{4}\right)$, location of the maxima at equal $\left(F_{1}, F_{2}\right)$ or at different $\left(F_{3}, F_{4}\right)$ distances from each other. Therefore, Deb's benchmark functions are widely used for experimental analysis of algorithms solving MMOPs. Having regard to the function properties two test suites for parameter tuning are composed:

- T1 includes functions $F_{2}$ and $F_{4}$ having one global and many local maxima;

- T2 includes functions $F_{1}$ and $F_{3}$ having many global and no local maxima.

\section{RESULTS}

The convergence of the MNGA with $F_{c h_{-} v}$ was not observed for any parameter set using binary codes; experiments were conducted for both $\mathrm{T} 1$ and $\mathrm{T} 2$ test suites. Therefore, parameter sets with binary codes were excluded from further analysis.

Results obtained for real number encoding and Gaussian density mutation, $P_{m}=1$, are given in Table 5 . It is easy to see from the table that the percentage of successful runs is poor in most cases. Moreover, it is worthwhile to consider only national selection method as far as MNGA $^{\mathrm{w}}{ }_{\mathrm{c} \mathrm{h}_{-} \mathrm{v}}$ converges only when $n=1$ while for MNGA $^{\mathrm{m}_{\mathrm{c} \_} \mathrm{C}_{-\mathrm{v}}}$ the SucRuns criterion value is close to $0 \%$.

We assume that proposed HVF modifications return wrong values more rarely in comparison with $F_{c h}$; thus, using $F_{m_{-} h_{-} v}$ or $F_{m_{-} h_{-} v_{\text {r }} \text { and }}$ instead of $F_{c h_{-} v}$ should improve the overall performance of the MNGA. With regard to above, the MNGA runs for classic HVF and its modifications were conducted using national selection method; results obtained for test suites $\mathrm{T} 1$ and $\mathrm{T} 2$ are given in Table 6. It is easy to see from the table that using HVF modifications gives higher percentage of successful runs for test suite $\mathrm{T} 1$, but decreases this percentage for test suite T2. Anyway, the SucRuns criterion value is still poor in most cases.

Assuming that another selection method tuned for appropriate HVF modification could improve the MNGA performance, the MNGA runs for different HVFs and different selection methods were conducted; both $\mathrm{T} 1$ and T2 test suites were used. Experiments have shown the thorough improvements of algorithm convergence. In particular, best results of SucRuns criterion were achieved by the $\mathrm{MNGA}^{\mathrm{w}}{ }_{\mathrm{m}_{-} \mathrm{h}_{-v}}(98.33 \%)$ and $\mathrm{MNGA}^{\mathrm{w}} \mathrm{m}_{-} \mathrm{h}_{-} \mathrm{v}_{-}$rand $(91.67 \%)$ on T1 test suite (functions having one global and many local maxima), and by the $\mathrm{MNGA}^{\mathrm{m}}{ }_{\mathrm{m}} \mathrm{h} \mathrm{v}$ $(100 \%)$ and $\mathrm{MNGA}^{\mathrm{w}}{ }_{\mathrm{m} \text { h v rand }}(100 \%)$ on $\mathrm{T} 2$ test suite (functions having many global and no local maxima). On the other hand, the quality criteria become worse with increasing the convergence criterion value, in particular, the $P R$ criterion value decreased 1.7-8.6 times. Supporting data (averages computed over all runs for functions $F_{1}-F_{4}$ ) are provided in Table 7 . Note that computation of averages over all benchmark functions makes sense as far as the function surfaces are not known in advance for most practical problems.

We have also developed the software implementation of the SCGA [29] intending to analyze this algorithm and to develop its hybridization with the MNGA; this seems to be a promising area $[16,17]$. Parameter tuning conducted for this algorithm led to the following parameter values: SUS selection, one-point mutation, $P_{m}=0.01$, no crossover, Euclidean distance, $\sigma_{\mathrm{s}}=0.2$. Experimental analysis of the SCGA with mentioned parameter values was conducted for functions $F_{1}-F_{4}$; results are given in Table 7. It is obvious from the table that though the SCGA provides satisfactory percentage of the algorithm convergence the quality parameter values of this algorithm are poor. 
e-ISSN 1607-3274 Радіоелектроніка, інформатика, управління. 2021. № 2 p-ISSN 2313-688X Radio Electronics, Computer Science, Control. 2021. № 2

Table 5 - Results of experiments: MNGA with classic HVF

\begin{tabular}{|c|c|c|c|c|c|c|c|c|c|c|}
\hline Parameters & \multicolumn{6}{|c|}{ Test suite T1 } & \multicolumn{4}{|c|}{ Test suite T2 } \\
\hline \multirow{2}{*}{$\begin{array}{l}\text { Selection } \\
\text { method }\end{array}$} & \multicolumn{5}{|c|}{ Criteria: average values over 10 runs } & \multirow{2}{*}{ Comment } & \multicolumn{3}{|c|}{$\begin{array}{c}\text { Criteria: average values } \\
\text { over } 10 \text { runs }\end{array}$} & \multirow{2}{*}{ Comment } \\
\hline & SucRuns & $P R$ & $G P R$ & $L P R$ & $F P R$ & & SucRuns & $P R=G P R$ & $F P R$ & \\
\hline Weighted & $31.67 \%$ & 0.2 & 0 & 0.25 & 0 & $\begin{array}{l}\text { Convergence } \\
\text { only if } n=1\end{array}$ & $16.67 \%$ & 1 & 0 & $\begin{array}{l}\text { Convergence } \\
\text { only if } n=1\end{array}$ \\
\hline National & $45 \%$ & 0.0898 & 0.4444 & 0.0749 & 0.7567 & & $93.33 \%$ & 0.5051 & 0.4287 & \\
\hline Mixed & $0 \%$ & & & & & & $2 \%$ & 0.9667 & 0.0040 & $\begin{array}{l}\text { Convergence } \\
\text { only for } F_{1}, \\
\text { if } n=1 \text { or } n=2\end{array}$ \\
\hline
\end{tabular}

Table 6 - Results of experiments: MNGA with classic HVF and its modifications

\begin{tabular}{|c|c|c|c|c|c|c|c|c|}
\hline \multirow{3}{*}{ Algorithm } & \multicolumn{5}{|c|}{ Test suite T1 } & \multicolumn{3}{|c|}{ Test suite T2 } \\
\hline & \multicolumn{5}{|c|}{ Criteria: average values over 10 runs } & \multicolumn{3}{|c|}{ Criteria: average values over 10 runs } \\
\hline & SucRuns & $P R$ & $G P R$ & $L P R$ & $F P R$ & SucRuns & $P R=G P R$ & $F P R$ \\
\hline $\mathrm{MNGA}_{\mathrm{ch} \mathrm{h}}^{\mathrm{n}}$ & $45 \%$ & 0.0898 & 0.4444 & 0.0749 & 0.7567 & $93.33 \%$ & 0.5051 & 0.4287 \\
\hline $\mathrm{MNGA}_{\mathrm{m} \mathrm{h}_{\mathrm{h}} \mathrm{v}}^{\mathrm{n}}$ & $63.33 \%$ & 0.6158 & 0.5790 & 0.6173 & 0.4173 & $68.33 \%$ & 0.6092 & 0.4361 \\
\hline $\mathrm{MNGA}_{\mathrm{m} \mathrm{h} \text { v rand }}^{\mathrm{n}}$ & $63.33 \%$ & 0.5737 & 0.6053 & 0.5680 & 0.3542 & $53.33 \%$ & 0.79 & 0.1919 \\
\hline
\end{tabular}

Table 7 - Results of experiments: MNGA with classic HVF and its modifications, SCGA, TCGM_S2; functions $F_{1}-F_{4}$

\begin{tabular}{|l|l|l|l|l|l|l|}
\hline \multirow{2}{*}{ Algorithm } & \multicolumn{5}{|c|}{ Criteria: average values over all runs } & Comment \\
\cline { 2 - 7 } & SucRuns & $P R$ & $G P R$ & $L P R$ & \\
\hline MNGA $_{\mathrm{c} \mathrm{h} \text { v }}^{\mathrm{n}}$ & $69.17 \%$ & 0.3700 & 0.4854 & 0.0749 & 0.5354 & \\
\hline MNGA $_{\mathrm{m} \mathrm{h} \mathrm{v}}$ & $65.83 \%$ & 0.6124 & 0.5946 & 0.6173 & 0.4270 & \\
\hline MNGA $_{\mathrm{m} \text { h v rand }}$ & $58.33 \%$ & 0.6726 & 0.6897 & 0.5680 & 0.280 & \\
\hline MNGA $_{\mathrm{m} \mathrm{h} \text { v }}$ & $99.17 \%$ & 0.1904 & 0.1799 & 0.0863 & 0.4622 & \\
\hline MNGA $_{\mathrm{m} \text { h v rand }}$ & $95.83 \%$ & 0.1908 & 0.2023 & 0.0735 & 0.2783 & \\
\hline SCGA & $90.83 \%$ & 0.2680 & 0.4481 & 0.025 & 0.6773 & \\
\hline TCGM_S2 & $100 \%$ & 0.9563 & 0.8908 & 0.4744 & 0.1538 & see [28] \\
\hline
\end{tabular}

\section{DISCUSSION}

From the Table 6 it follows that using HVF modifications improves the performance of the MNGA solving optimization problems for functions having global and local maxima. Indeed, the SucRuns increased by nearly $41 \%$, the $P R$ increased nearly 6.86 times for $F_{m_{-} h_{-} v}$ and 6.39 times for $F_{m h v \text { rand }}$ (mainly due to the greater number of local peaks found), the FPR decreased significantly, to be exact by $55 \%$ for $F_{m_{-} h_{-} v}$ and by $47 \%$ for $F_{m h_{\nu} v_{\text {rand }} \text {. Let us remark that } F_{m} h_{v} \text { rand }}$ gives better results in comparison with $F_{m-h v}$ in terms of GPR and FPR, but worse results in terms of $L P R$. Fig. 3 illustrates the forgoing via a histogram.

Now let us analyze the influence of $F_{m_{-} h_{-} v}$ and $F_{m_{-} h_{-} v-}$ rand on performance of the MNGA solving optimization problems for functions having only global maxima. From the Table 6 we see that SucRuns decreased considerably, namely by $27 \%$ for $F_{m_{-} h_{-} v}$ and by $43 \%$ for $F_{m_{-} h_{-} v_{-} \text {rand }}$. At the same time, the $P R$ increased by $21 \%$ for $F_{m} h_{v}$ and by

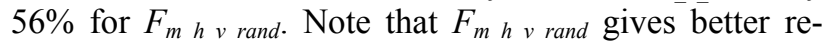
sults in comparison with $F_{m_{-} h_{-} v}$ in terms of GPR and FPR, but provides worse algorithm convergence. Fig. 4 illustrates the forgoing via a histogram.

Consequently, the performance improvement of the MNGA using HVF modifications can be observed when the objective function has global and local maxima. If the objective function has only global maxima, the quality criteria improvement is accompanied by the decrease of the convergence criterion value.

Let us consider other test functions. Functions $F_{8}$ and $F_{9}$ have only global maxima. Experiments conducted for these functions of dimensions 1 and 2 showed $100 \%$ of convergence and GPR value close to 1 for all three kinds (C) Gulayeva N. M., Yaremko S. A., 2021 DOI $10.15588 / 1607-3274-2021-2-8$ of the algorithm: $\mathrm{MNGA}_{\mathrm{c}_{-} \mathrm{h}-\mathrm{v}}^{\mathrm{n}}, \quad \mathrm{MNGA}_{\mathrm{m}_{-} \mathrm{h}-\mathrm{v}}^{\mathrm{n}}$, $\mathrm{MNGA}^{\mathrm{n}}{ }_{\mathrm{m} \_ \text {h_v_rand. }}$.

Functions $F_{5}, F_{6}$ and $F_{7}$ have global and local maxima. Experiments conducted for functions $F_{5}$ of dimension 2 and $F_{7}$ of dimensions 1,2 and 3 revealed the advantage of modified HVFs over classic HVF in terms of $P R$ (mainly due to the greater number of local peaks found). However, modified HVFs provide worse algorithm convergence. Function $F_{6}$ is defined on the wide range of argument values; therefore, to find maxima of $F_{6}$ the population size parameter of the MNGA was increased to 1000 individuals. Experiments were conducted for function $F_{6}$ of dimensions 1, 2 and 3. The $\mathrm{MNGA}^{\mathrm{n}}{ }_{\mathrm{m}_{-} \mathrm{h}_{\mathrm{v}}}$ algorithm demonstrated significantly better results both in terms of convergence and quality of found solutions: $\mathrm{Su}$ cRuns $=90 \%$ for $\mathrm{MNGA}_{\mathrm{m} \mathrm{h}_{\mathrm{v}}}^{\mathrm{n}}$ and SucRuns $=50 \%$ for $\mathrm{MNGA}_{\mathrm{c}_{-} \mathrm{h} \_\mathrm{v}}^{\mathrm{n}}, \quad G P R=0.407 \overline{4}$ for $\mathrm{MNGA}^{\mathrm{n}}{ }_{\mathrm{m} \_\mathrm{h} \mathrm{v}}$ and $G P R=0.26 \overline{6} 7$ for $\mathrm{MNGA}^{\mathrm{n}}{ }_{\mathrm{c} \_ \text {h_v }}$.

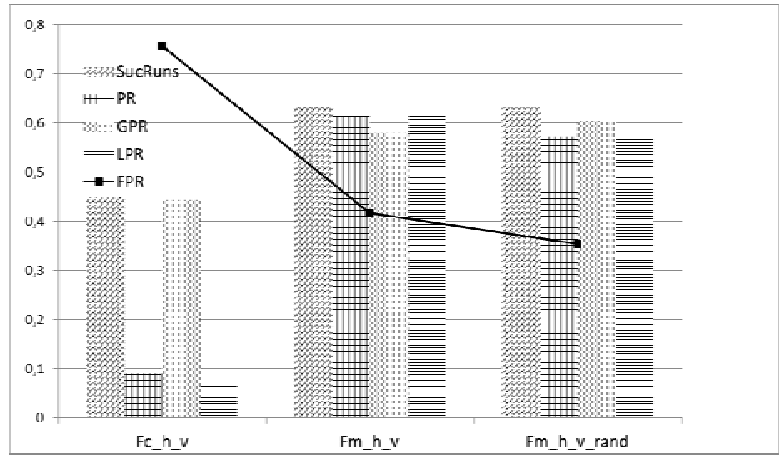

Figure 3 - Histogram with criteria values obtained for MNGA using different HVFs, test suite T1 


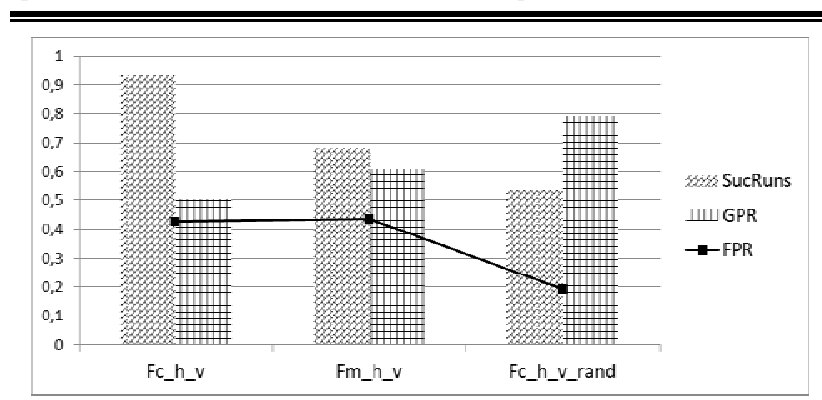

$\overline{\text { Figure } 4 \text { - Histogram with criteria values obtained for MNGA }}$ using different HVFs, test suite T2

From the stated above it can be concluded that $\mathrm{MNGA}_{\mathrm{m}_{\mathrm{h}} \mathrm{v}}^{\mathrm{n}}$ performance is either close to the performance of $\overline{M N G A}{ }_{{ }_{\mathrm{c} h \mathrm{v}}}$ or is better in terms of $P R$; at the same time improvements in $P R$ are accompanied by the decrease of SucRuns for some functions. This is also the case for the $\mathrm{MNGA}_{\mathrm{m}_{\mathrm{h}} \mathrm{v}_{\text {_rand }} \text {, though }}^{\mathrm{n}} \mathrm{MNGA}_{\mathrm{m}_{-} \mathrm{h} \_ \text {r rand }}^{\mathrm{n}}$ often gives worse results than the $\mathrm{MNGA}_{\mathrm{m}_{-} \mathrm{h}_{-} \mathrm{v}}^{\mathrm{n}}$, especially in terms of convergence.

By analyzing data from Table 7 providing benchmarking results for functions $F_{1}-F_{4}$ we can state that generally all kinds of MNGA studied in this research are unacceptable for practical use as far as they are characterized either by low value of convergence criterion (that is less than $90 \%$ ) or by low ratio of real peaks and high ratio of fake peaks found by the algorithm. This is also true for other test functions. As for $F_{9}$, there are observed $\mathrm{Su}$ cRuns $=100 \%$ and GPR value close to 1 for all kinds of MNGA. This can be explained by the specific surface of $F_{9}$ : the function curve is a plateau with four peaks close to each other. Such a surface is a challenge for most optimization algorithms but turned to be solvable for MNGA.

Note that all experiments in our study are conducted for test functions of small dimensions $(1 \leq n \leq 3)$. The reason is the long algorithm execution time caused by a number of factors including the low convergence percentage. For example, the $\mathrm{MNGA}^{\mathrm{n}}{ }_{\mathrm{m}_{-} \mathrm{h}_{-} \mathrm{v}}, \mathrm{MNGA}^{\mathrm{w}}{ }_{\mathrm{m}_{-} \mathrm{h}_{-} \mathrm{v}}$, $\mathrm{MNGA}^{\mathrm{m}}{ }_{\mathrm{m} \_\mathrm{h} \_\mathrm{v}}$ running time to find optimums of $F_{5}-\bar{F}_{9}$ took about $\overline{4} 8$ hours. The computer configuration used to run these algorithms was the following: processor Intel(R) Core(TM) i5-7200U CPU @ 2.50GHz 2.71 GHz; 8.00 GB RAM (7.88 GB available); 64-bit Windows 10 operating system, x64 processor, 2 cores, 4 logic processors.

\section{CONCLUSIONS}

In this paper, the MNGA parameter tuning was carried out and experimental analysis of the MNGA performance was conducted. Two modifications of the HVF used to determine the relative position of individuals were proposed. Benchmarking of MNGA with classic HVF and with its modifications was carried out. Experiments showed that proposed modifications had increased the number of real extrema found by the algorithm for most test functions. Stated above determines the scientific novelty of the obtained results.

The practical significance of the obtained results lies in the following statements.

(C) Gulayeva N. M., Yaremko S. A., 2021

DOI 10.15588/1607-3274-2021-2-8
- First, as HVF modifications produce less number of wrong basin identifications in comparison with classic $\mathrm{HVF}$, it is recommended to use $F_{m_{-} h_{-}}, F_{m_{-} h_{-} v_{-} \text {rand }}$ in other GAs using HVF [16-25].

- Secondly, as the overall performance of MNGA is poor in comparison with other known GAs, the MNGA is not recommended for practical use.

Indeed, GAs solving multimodal optimization problems, i.e. the problems of finding several optimums, contribute to grouping individuals of final population into species so that the best individual of each species represents one of the sought optimums. Obviously, it is worthwhile to analyze groups of individuals only in case of GA convergence. Generally, the number and location of function optimums are not known a priory for practical problems. It is known, that individuals of the GA final population may be located in the neighborhoods of function peaks as well as far from them, clustering on peak slopes or even in the valleys. Therefore, to choose an algorithm to solve practical MMOPs, in particular problems of finding global and local peaks, it is important to analyze criteria representing number of real peaks found by the algorithm as well as number of fake species formed by the algorithm. These are the $P R, G P R, L P R$ and FPR criteria.

Experimental analysis of the MNGA with both classic HVF and its modifications has revealed the unacceptably low value of the convergence criterion (SucRuns $<90 \%$ ) and unacceptable for practical use values of the quality criteria, i.e. small values of $P R, G P R, L P R$ accompanied by the high value of the $F P R$. Generally, depending on algorithm parameter values there is observed either improvement of quality criteria values accompanied by the worse algorithm convergence or higher convergence percentage accompanied by deterioration of quality criteria values. Note that quality parameter values of the SCGA algorithm developed for farther hybridization [16, 17] with MNGA are also poor. Let us remark that in [28] there was proposed TCGM_S2 algorithm; criterion values computed in [28] for this algorithm are given in Table 7. It is readily seen that this algorithm provides better criterion values in terms of convergence percentage as well as in terms of quality of the solutions found. Thus it is reasonable to say that it is impractical to use MNGA to find global and local optima of a multimodal function. On the other hand, hybridizations of MNGA with other algorithms could be an option.

Let us remark that there still exist situations when $F_{m_{-} h_{-} v}, F_{m_{-} h_{-} v_{-} \text {rand }}$ return wrong values. Let us consider function $F_{1}$ and sample array $g r=[0.02,0.25,0.5,0.75$, 0.98 ] from [15]. Points 0.0 and 1.0 are wrongly attributed to the same basin of attraction by both $F_{c h v}$ and $F_{m-h v}$; return value of $F_{m_{-} h_{-} v_{-} \text {rand }}$ is wrong with a certain probability. To overcome this, modifications of $F_{m_{-} h_{-} v}$ can be proposed. Modifications regarding a method to construct sequences of sample points are an option. Several of these were proposed in $[18-20,24,30]$, e.g. replacement of equidistant test points by a golden section search or changing quantity of test points dependent on the distance between individuals. 
In [14] it is stated that MNGA forms only one subpopulation in the neighborhood of every peak. Preliminary experiments have shown that using HVF to determine species (niches) formed by the final population instead of the algorithm used in this research (the algorithm from [28]) gives better results in terms of FPR. At the same time SucRuns, PR, GPR and LPR criteria values obviously stay the same. We believe it is worth to conduct benchmarking of different niching GAs using HVF or its modifications as the algorithm to determine species (or, equivalently, as a post-processing step for every algorithm after its convergence).

Thus, we see two main directions for further research: improvements of the HVF and using HVF as a post-processing step for other niching GAs. This will be the object of another paper.

\section{ACKNOWLEDGEMENTS}

Authors express great appreciations to their colleges from the National University of "Kyiv-Mohyla Academy", Head of the Department of Informatics S. S. Gorokhovskyi and Professor of the Department of Informatics M. M. Glybovets, for their valuable remarks on the obtained results.

\section{REFERENCES}

1. Li X., Epitropakis M. G., Deb K. et al. Seeking Multiple Solutions: An Updated Survey on Niching Methods and Their Applications, IEEE Transactions on Evolutionary Computation, 2017, Vol. 21, No. 4, pp. 518-538. DOI: 10.1109/TEVC.2016.2638437.

2. Shen Z.-H., Zhao Y.-K., Wu W.-W. Niche Pseudo-Parallel Genetic Algorithms for Path Optimization of Autonomous Mobile Robot, Journal of Shanghai University (English Edition), 2006, Vol. 10, No. 5, pp. 449-453. DOI: 10.1007/s11741-006-0089-3.

3. Preuss M., Liapis A., Togelius J. Searching for Good and Diverse Game Levels, IEEE Conference on Computational Intelligence and Games, Dortmund, 26-29 August, 2014: proceedings. Piscataway, IEEE, 2014, pp. 1-8. DOI: 10.1109/CIG.2014.6932908.

4. Chica M., Barranquero J., Kajdanowicz T. et al. Multimodal Optimization: an Effective Framework for Model Calibration, Information Sciences, 2017, Vol. 375, pp. 79-97. DOI: 10.2139/ssrn.2828069.

5. Leoshchenko S. D., Oliinyk A. O., Subbotin S. A. et al. Modification and Parallelization of Genetic Algorithm For Synthesis of Artificial Neural Networks, Radio Electronics, Computer Science, Control, 2019, No. 4, pp. 68-82. DOI: 10.15588/1607-3274-2019-4-7.

6. Glybovets M. M., Gulayeva N. M., Butenko S., Pardalos P. M., Shylo V. (eds.). Evolutionary Multimodal Optimization, Optimization methods and applications. In honor of Ivan $V$. Sergienko's 80th birthday. Cham, Springer, 2017, pp. 129 173. DOI: 10.1007/978-3-319-68640-0_8. (Series "Springer Optimization and Its Applications")

7. Preuss M. Multimodal Optimization by Means of Evolutionary Algorithms. Berlin, Springer, 2015, 175 p. DOI: 10.1007/978-3-319-07407-8.

8. Törn A., Viitanen S., Floudas C. A., Pardalos P. M. (eds.), Topographical Global Optimization, Recent Advances in
Global Optimization. Princeton University Press, 1992, pp. 384-398. DOI: 10.1515/9781400862528.384.

9. Wessing S., Preuss M. The True Destination of EGO is Multi-Local Optimization, IEEE Latin American Conference on Computational Intelligence (LA-CCI), Arequipa, 8-10 November, 2017, proceedings. Piscataway, IEEE, 2017, pp. 1-6. DOI: 10.1109/LA-CCI.2017.8285677.

10. Preuss M. Niching the CMA-ES via Nearest-Better Clustering, Genetic and Evolutionary Computation Conference (GECCO), Portland, 7-11 July, 2010: proceedings. New York, ACM, 2010, pp. 1711-1718. DOI: 10.1145/1830761.1830793.

11. Preuss M., Di Chio C., Agapitos A., Cagnoni S. et al. (eds.)Improved Topological Niching for Real-Valued Global Optimization, Applications of Evolutionary Computation (EvoApplications), Málaga, 11-13 April, 2012: proceedings. Berlin, Springer, 2012, Vol. 7248, pp. 386-395. DOI: 10.1007/978-3-642-29178-4 39. (Series "Lecture Notes in Computer Science")

12. Li Y., Yu J., Takagi H. Niche Method Complementing the Nearest-Better Clustering, IEEE Symposium Series on Computational Intelligence (SSCI), Xiamen, 6-9 December, 2019: proceedings. Piscataway, IEEE, 2019, pp. 3065-3071. DOI: $10.1109 /$ SSCI44817.2019.9002742.

13. Luo W. Qiao Y., Lin X. et al. Hybridizing Niching, Particle Swarm Optimization, and Evolution Strategy for Multimodal Optimization, IEEE Transactions on Cybernetics: early access article, 2020. DOI: 10.1109/TCYB.2020.3032995.

14. Ursem R. K. Multinational Evolutionary Algorithms / R. K. Ursem // Congress on Evolutionary Computation (CEC99), Washington, 6-9 July, 1999, proceedings. Piscataway, IEEE, 1999, Vol. 3, pp. 1633-1640. DOI: 10.1109/CEC.1999.785470.

15. Ursem R. K. Multinational GAs: Multimodal Optimization Techniques in Dynamic Environments, Genetic and Evolutionary Computation Conference (GECCO), Las Vegas, 812 July, 2000, proceedings. San Francisco, Morgan Kaufmann, 2000, Vol. 1, pp. 19-26.

16. Stoean C., Preuss M., Stoean R. et al. Disburdening the Species Conservation Evolutionary Algorithm of Arguing with Radii, Genetic and Evolutionary Computation Conference (GECCO), London, 7-11 July, 2007: proceedings. New York, ACM, 2007, pp. 1420-1427. DOI: $10.1145 / 1276958.1277220$.

17. Stoean C., Preuss M., Stoean R. et al. Multimodal Optimization by Means of a Topological Species Conservation Algorithm, IEEE Transactions on Evolutionary Computation, 2010, Vol. 14, No. 6, pp. 842-864. DOI: 10.1109/TEVC.2010.2041668.

18. Cioppa A. D., Marcelli A., Napoli P. Speciation in Evolutionary Algorithms: Adaptive Species Discovery, Genetic and Evolutionary Computation Conference (GECCO), Dublin, 12-16 July, 2011: proceedings. New York, ACM, 2011, pp. 1053-1060. DOI: 10.1145/2001576.2001719.

19. Li L., Tang K. History-Based Topological Speciation for Multimodal Optimization, IEEE Transactions on Evolutionary Computation, 2015, Vol. 19, No. 1, pp. 136-150. DOI: 10.1109/TEVC.2014.2306677.

20. Maree S. C., Alderliesten T., Thierens D. et al. Real-Valued Evolutionary Multi-Modal Optimization Driven by HillValley Clustering, Genetic and Evolutionary Computation Conference (GECCO), Kyoto, 15-19 July, 2018: proceedings. New York, ACM, 2018, pp. 857-864. DOI: $10.1145 / 3205455.3205477$. 
21. Maree S. C., Alderliesten T., Bosman P. A. N. Benchmarking HillVallEA for the GECCO 2019 Competition on Multimodal Optimization [Electronic resource], 2019. Access mode: https://arxiv.org/abs/1907.10988.

22. Navarro R., Kim C. H. Niching Multimodal Landscapes Faster Yet Effectively: VMO and HillVallEA Benefit Together, Mathematics, 2020, Vol. 8, No. 5 (665). DOI: 10.3390/math8050665.

23. Navarro R., Kim C. H. Improved Population Control for More Efficient Multimodal Optimizers, Congreso Internacional de Innovación y Tendencias en Ingeniería (CONIITI), Bogotá, 30 September - 2 October, 2020: proceedings. Piscataway, IEEE, 2020, pp. 1-6. DOI: 10.1109/CONIITI51147.2020.9240365.

24. Ahrari A., Deb K., Preuss M. Multimodal Optimization by Covariance Matrix Self-Adaptation Evolution Strategy with Repelling Subpopulations, Evolutionary Computation, 2017. Vol. 25, No. 3, pp. 439-471. DOI: 10.1162/evco a 00182.

25. Ahrari A., Deb K., Preuss M. Benchmarking Covariance Matrix Self Adaption Evolution Strategy with Repelling Subpopulations for GECCO 2017 Competition on Multimodal Optimization : technical report : 2017014, Computational Optimization and Innovation Laboratory (COIN), Michigan State University. Michigan, 2017, 5 p.
26. Jamil M., Yang X.-S. A Literature Survey of Benchmark Functions for Global Optimization Problems / M. Jamil, // International Journal of Mathematical Modelling and Numerical Optimisation, 2013, Vol. 4, No. 2, pp. 150-194. DOI: 10.1504/IJMMNO.2013.055204.

27. Li X., Engelbrecht A., Epitropakis M. G. Benchmark Functions for CEC'2013 Special Session and Competition on Niching Methods for Multimodal Function Optimization : report, Evolutionary Computation and Machine Learning Group, RMIT University. Melbourne, 2013, 10 p.

28. Shylo V. P., Glybovets M. M., Gulayeva N. M. et al.Genetic Algorithm of Tournament Crowding Based on Gaussian Mutation, Cybernetics and Systems Analysis, 2020, Vol. 56, No. 2, pp. 231-242. DOI: 10.1007/s10559-020-00239-4.

29. Li J.-P., Balazs M. E., Parks G. T. et al. A Species Conserving Genetic Algorithm for Multimodal Function Optimization, Evolutionary Computation, 2002, Vol. 10, No. 3, pp. 207-234. DOI: 10.1162/106365602760234081.

30. Yao J., Kharma N., Grogono P. Bi-Objective Multipopulation Genetic Algorithm for Multimodal Function Optimization, IEEE Transactions on Evolutionary Computation, 2010, Vol. 14, No. 1, pp. 80-102. DOI: 10.1109/TEVC.2009.2017517.

Received 25.01.2021. Accepted 23.04.2021

УДК 004.023

\section{ЕКСПЕРИМЕНТАЛЬНИЙ АНАЛІЗ БАГАТОНАЦІОНАЛЬНОГО ГЕНЕТИЧНОГО АЛГОРИТМУ ТА ЙОГО МОДИФІКАЦІЙ}

Гулаєва Н. М. - канд. фіз.-мат. наук, доцент, доцент кафедри інформатики Національного університету «КиєвоМогилянська академія», Київ, Україна.

Яремко С. А. - магістр, асистент кафедри інформатики Національного університету «Києво-Могилянська академія», Київ, Україна.

\section{АНОТАЦІЯ}

Актуальність. Генетичні алгоритми утворення ніш $\epsilon$ одним 3 найпоширеніших підходів до розв'язання задач багатоекстремальної оптимізації. При проведенні класифікації цих алгоритмів можна виділити алгоритми, що грунтуються на явному аналізі топографії ландшафту функції пристосованості. Одним 3 ранніх прикладів таких алгоритмів $\epsilon$ багатонаціональний генетичний алгоритм.

Мета. Розробка та аналіз багатонаціонального генетичного алгоритму та його модифікацій. Алгоритм застосовується для розв'язання задачі пошуку всіх максимумів багатоекстремальної функції.

Метод. Виконано експериментальний аналіз алгоритмів. Проведено численні прогони алгоритмів на відомих тестових задачах та обчислено критерії ефективності роботи алгоритмів, а саме, відсоток збіжності, частка реальних (глобальних, локальних) та хибних піків; зауважимо, що частки піків обчислюються тільки в разі збіжності алгоритму.

Результати. Виконано програмну реалізацію багатонаціонального генетичного алгоритму та проведено експериментальне налаштування його параметрів. Запропоновано дві модифікації функції долин і пагорбів, яка використовується в алгоритмі для визначення взаємного розташування особин. Проведено експериментальний аналіз багатонаціонального генетичного алгоритму з класичного функцією долин і пагорбів та з їі модифікаціями.

Висновки. Наукова новизна роботи полягає в тому, що були запропоновані модифікації функції долин і пагорбів, які продукують меншу кількість помилкових ідентифікацій зон притягання порівняно з класичним варіантом цієї функції. Як наслідок, використання цих модифікацій призводить до покращення продуктивності багатонаціонального генетичного алгоритму для низки тестових задач. Втім, для деяких тестових задач поліпшення критеріїв якості супроводжується зменшенням відсотка збіжності. Загалом, відсоток збіжності та значення критеріїв якості, продемонстровані дослідженим алгоритмом, $\epsilon$ недостатніми для практичного використання багатонаціонального генетичного алгоритму у порівнянні 3 іншими відомими алгоритмами. У той же час, використання модифікованих функцій долин і пагорбів як етапу постобробки в інших алгоритмах утворення ніш видається перспективним підходом до покращення роботи цих алгоритмів.

КЛЮЧОВІ СЛОВА: задача багатоекстремальної оптимізації, генетичні алгоритми утворення ніш, багатонаціональний генетичний алгоритм, функція долин і пагорбів, збіжність генетичного алгоритму, частка реальних піків, частка хибних піків. 


\section{ЭКСПЕРИМЕНТАЛЬНЫЙ АНАЛИЗ МНОГОНАЦИОНАЛЬНОГО ГЕНЕТИЧЕСКОГО АЛГОРИТМА И ЕГО МОДИФИКАЦИЙ}

Гулаева Н. М. - канд. физ.-мат. наук, доцент, доцент кафедры информатики Национального университета «КиевоМогилянская академия», Киев, Украина.

Яремко С. А. - магистр, ассистент кафедры информатики Национального университета «Киево-Могилянская академия», Киев, Украина.

\section{АННОТАЦИЯ}

Актуальность. Генетические алгоритмы образования ниш являются одним из самых распространенных подходов к решению задач многоэкстремальной оптимизации. При проведении классификации генетических алгоритмов образования ниш можно выделить алгоритмы, основанные на явном анализе топографии ландшафта функции приспособленности. Многонациональный генетический алгоритм является одним из ранних примеров таких алгоритмов.

Цель. Разработка и анализ многонационального генетического алгоритма и его модификаций. Алгоритм применяется для решения задачи поиска всех максимумов многоэкстремальной функции.

Метод. Выполнен экспериментальный анализ алгоритмов. Проведены многочисленные прогоны алгоритмов на известных тестовых задачах и вычислены критерии эффективности работы алгоритмов, а именно, процент сходимости, доля реальных (глобальных, локальных) и ложных пиков; отметим, что доля пиков вычисляется только в случае сходимости алгоритма.

Результаты. Выполнена программная реализация многонационального генетического алгоритма и проведена экспериментальная настройка его параметров. Предложены две модификации функции холмов и долин, используемой в алгоритме для определения взаимного расположения особей. Выполнен экспериментальный анализ многонационального генетического алгоритма с классической функцией холмов и долин и с ее модификациями.

Выводы. Научная новизна работы состоит в том, что были предложены модификации функции холмов и долин, приводящие к меньшему количеству неправильных определений зон притяжения по сравнению с классическим вариантом этой функции. Как следствие, использование этих модификаций приводит к повышению производительности многонационального генетического алгоритма для ряда тестовых задач. Однако для некоторых тестовых задач улучшение критериев качества сопровождается уменьшением процента сходимости. В целом, процент сходимости и значения критериев качества, продемонстрированные исследуемым алгоритмом, недостаточны для практического использования многонационального генетического алгоритма по сравнению с другими известными алгоритмами. В то же время, использование модифицированных функций холмов и долин в качестве шага постобработки в других алгоритмах образования ниш представляется многообещающим подходом к улучшению производительности этих алгоритмов.

КЛЮЧЕВЫЕ СЛОВА: задача многоэкстремальной оптимизации, генетические алгоритмы образования ниш, многонациональный генетический алгоритм, функция холмов и долин, сходимость генетического алгоритма, доля реальных пиков, доля ложных пиков.

ЛІТЕРАТУРА / ЛИТЕРАТУРА

1. Li X. Seeking Multiple Solutions: An Updated Survey on Niching Methods and Their Applications / [X. Li, M. G. Epitropakis, K. Deb et al.] // IEEE Transactions on Evolutionary Computation. - 2017. - Vol. 21, № 4. - P. 518-538. DOI: 10.1109/TEVC.2016.2638437.

2. Shen Z.-H. Niche Pseudo-Parallel Genetic Algorithms for Path Optimization of Autonomous Mobile Robot / Z.-H. Shen, Y.-K. Zhao, W.-W. Wu // Journal of Shanghai University (English Edition). - 2006. - Vol. 10, № 5. P. 449-453. DOI: 10.1007/s11741-006-0089-3.

3. Preuss M. Searching for Good and Diverse Game Levels M. Preuss, A. Liapis, J. Togelius // IEEE Conference on Computational Intelligence and Games, Dortmund, 26-29 August, 2014: proceedings. - Piscataway: IEEE, 2014. P. 1-8. DOI: 10.1109/CIG.2014.6932908.

4. Chica M. Multimodal Optimization: an Effective Framework for Model Calibration / [M. Chica, J. Barranquero, T. Kajdanowicz et al.] // Information Sciences. - 2017. Vol. 375. - P. 79-97. DOI: 10.2139/ssrn.2828069.

5. Leoshchenko S. D. Modification and Parallelization of Genetic Algorithm For Synthesis of Artificial Neural Networks / [S. D. Leoshchenko, A. O. Oliinyk, S. A. Subbotin et al.] // Radio Electronics, Computer Science, Control. - 2019. № 4. - P. 68-82. DOI: 10.15588/1607-3274-2019-4-7.

6. Glybovets M. M. Evolutionary Multimodal Optimization / M. M. Glybovets, N. M. Gulayeva // Optimization methods and applications. In honor of Ivan V. Sergienko's 80th birthday / S. Butenko, P. M. Pardalos, V. Shylo (eds.). Cham : Springer, 2017. - P. 129-173. DOI: 10.1007/978-3319-68640-0_8. - (Series "Springer Optimization and Its Applications")

7. Preuss M. Multimodal Optimization by Means of Evolutionary Algorithms / M. Preuss. - Berlin : Springer, 2015. 175 p. DOI: 10.1007/978-3-319-07407-8.

8. Törn A. Topographical Global Optimization / A. Törn, S. Viitanen ; C. A. Floudas, P. M. Pardalos (eds.) // Recent Advances in Global Optimization. - Princeton University Press, 1992. - P. 384-398. DOI: $10.1515 / 9781400862528.384$.

9. Wessing S. The True Destination of EGO is Multi-Local Optimization / S. Wessing, M. Preuss // IEEE Latin American Conference on Computational Intelligence (LA-CCI), Arequipa, 8-10 November, 2017: proceedings. - Piscataway: IEEE, 2017. - P. 1-6. DOI: 10.1109/LACCI.2017.8285677.

10. Preuss M. Niching the CMA-ES via Nearest-Better Clustering / M. Preuss // Genetic and Evolutionary Computation Conference (GECCO), Portland, 7-11 July, 2010: proceedings. - New York: ACM, 2010. - P. 1711-1718. DOI: 10.1145/1830761.1830793.

11. Preuss M. Improved Topological Niching for Real-Valued Global Optimization / M. Preuss // Applications of Evolutionary Computation (EvoApplications), Málaga, 11-13 
April, 2012: proceedings / Di Chio C., Agapitos A., Cagnoni S. et al. (eds.). - Berlin: Springer, 2012. - Vol. 7248. P. 386-395. DOI: 10.1007/978-3-642-29178-4_39. - (Series "Lecture Notes in Computer Science")

12. Li Y. Niche Method Complementing the Nearest-Better Clustering / Y. Li, J. Yu, H. Takagi // IEEE Symposium Series on Computational Intelligence (SSCI), Xiamen, 6-9 December, 2019: proceedings. - Piscataway: IEEE, 2019. P. 3065-3071. DOI: 10.1109/SSCI44817.2019.9002742.

13. Luo W. Hybridizing Niching, Particle Swarm Optimization, and Evolution Strategy for Multimodal Optimization / [W. Luo, Y. Qiao, X. Lin et al.] // IEEE Transactions on Cybernetics: early access article. - 2020. DOI: 10.1109/TCYB.2020.3032995.

14. Ursem R. K. Multinational Evolutionary Algorithms / R. K. Ursem // Congress on Evolutionary Computation (CEC99), Washington, 6-9 July, 1999: proceedings. - Piscataway: IEEE, 1999. - Vol. 3. - P. 1633-1640. DOI: 10.1109/CEC.1999.785470.

15. Ursem R. K. Multinational GAs: Multimodal Optimization Techniques in Dynamic Environments / R. K. Ursem // Genetic and Evolutionary Computation Conference (GECCO), Las Vegas, 8-12 July, 2000: proceedings. - San Francisco: Morgan Kaufmann, 2000. - Vol. 1. - P. 19-26.

16. Stoean C. Disburdening the Species Conservation Evolutionary Algorithm of Arguing with Radii / [C. Stoean, M. Preuss, R. Stoean et al.] // Genetic and Evolutionary Computation Conference (GECCO), London, 7-11 July, 2007: proceedings. - New York: ACM, 2007. - P. 1420-1427. DOI: 10.1145/1276958.1277220.

17. Stoean C. Multimodal Optimization by Means of a Topological Species Conservation Algorithm / [C. Stoean, M. Preuss, R. Stoean et al.] // IEEE Transactions on Evolutionary Computation. - 2010. - Vol. 14, № 6. - P. 842-864. DOI: 10.1109/TEVC.2010.2041668.

18. Cioppa A. D. Speciation in Evolutionary Algorithms: Adaptive Species Discovery / A. D. Cioppa, A. Marcelli, P. Napoli // Genetic and Evolutionary Computation Conference (GECCO), Dublin, 12-16 July, 2011: proceedings. - New York, ACM, 2011. - P. 1053-1060. DOI: $10.1145 / 2001576.2001719$.

19. Li L. History-Based Topological Speciation for Multimodal Optimization / L. Li, K. Tang // IEEE Transactions on Evolutionary Computation. - 2015. - Vol. 19, №. 1. - P. 136150. DOI: 10.1109/TEVC.2014.2306677.

20. Maree S. C. Real-Valued Evolutionary Multi-Modal Optimization Driven by Hill-Valley Clustering / [S. C. Maree, T. Alderliesten, D. Thierens et al.] // Genetic and Evolutionary Computation Conference (GECCO), Kyoto, 15-19 July, 2018: proceedings. - New York, ACM, 2018. - P. 857-864. DOI: $10.1145 / 3205455.3205477$
21. Maree S. C. Benchmarking HillVallEA for the GECCO 2019 Competition on Multimodal Optimization [Electronic resource] / S. C. Maree, T. Alderliesten, P. A. N. Bosman. 2019. - Access mode: https://arxiv.org/abs/1907.10988.

22. Navarro R. Niching Multimodal Landscapes Faster Yet Effectively: VMO and HillVallEA Benefit Together / R. Navarro, C. H. Kim // Mathematics. - 2020. - Vol. 8, №5 (665). DOI: 10.3390/math8050665.

23. Navarro R. Improved Population Control for More Efficient Multimodal Optimizers / R. Navarro, C. H. Kim // Congreso Internacional de Innovación y Tendencias en Ingeniería (CONIITI), Bogotá, 30 September -2 October, 2020: proceedings. - Piscataway: IEEE, 2020. - P. 1-6. DOI: 10.1109/CONIITI51147.2020.9240365.

24. Ahrari A. Multimodal Optimization by Covariance Matrix Self-Adaptation Evolution Strategy with Repelling Subpopulations / A. Ahrari, K. Deb, M. Preuss // Evolutionary Computation. - 2017. - Vol. 25, № 3. - P. 439-471. DOI: 10.1162/evco_a_00182.

25. Ahrari A. Benchmarking Covariance Matrix Self Adaption Evolution Strategy with Repelling Subpopulations for GECCO 2017 Competition on Multimodal Optimization : technical report : 2017014 / A. Ahrari, K. Deb, M. Preuss / Computational Optimization and Innovation Laboratory (COIN), Michigan State University. - Michigan, 2017. - 5 p.

26. Jamil M. A Literature Survey of Benchmark Functions for Global Optimization Problems / M. Jamil, X.-S. Yang // International Journal of Mathematical Modelling and Numerical Optimisation. - 2013. - Vol. 4, № 2. - P. 150-194. DOI: 10.1504/IJMMNO.2013.055204.

27. Li X. Benchmark Functions for CEC'2013 Special Session and Competition on Niching Methods for Multimodal Function Optimization : report / X. Li, A. Engelbrecht, M. G. Epitropakis / Evolutionary Computation and Machine Learning Group, RMIT University. - Melbourne, 2013. $10 \mathrm{p}$.

28. Шило В. П. Генетичні алгоритми турнірного витиснення 3 гаусовою мутацією / [В. П. Шило, М. М. Глибовець, Н. М. Гулаєва та ін.] // Кибернетика и системный анализ. - 2020. - Том 56, № 2. - С.75-88

29. Li J.-P. A Species Conserving Genetic Algorithm for Multimodal Function Optimization / [J.-P. Li, M. E. Balazs, G. T. Parks et al.] // Evolutionary Computation. - 2002. Vol. 10, № $3 . \quad-\quad$ P. 207-234. DOI: $10.1162 / 106365602760234081$.

30. Yao J. Bi-Objective Multipopulation Genetic Algorithm for Multimodal Function Optimization / J. Yao, N. Kharma, P. Grogono // IEEE Transactions on Evolutionary Computation. - 2010. - Vol. 14, № 1. - P. 80-102. DOI: 10.1109/TEVC.2009.2017517. 